\title{
Erratum to: The Long and Short of Genetic Counseling Letters: A Case-control Study
}

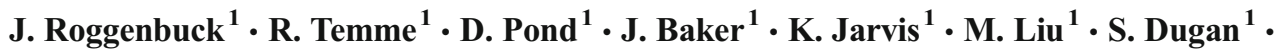 \\ N. J. Mendelsohn ${ }^{1}$
}

Published online: 3 November 2015

(C) National Society of Genetic Counselors, Inc. 2015

\section{Erratum to: J Genet Counsel DOI 10.1007/s10897-014-9792-6}

We would like to note the following corrections to the above paper:

- On page 648, under the subheading 'Parental Rating of Genetic Counseling Letter', the final sentence of the third paragraph should read, "Total dimension scores indicated that case parents had a more positive overall emotional response to the letter $(p=0.039)$." We have provided an additional figure showing letter dimension scores in control and case groups, for further clarification; see Figure 1 in this erratum.

- On page 648, under the subheading 'Parental Rating of Genetic Counseling Letter', the first sentence of the fourth paragraph should read, "Summing scores across all three dimensions, case parents (who received the short letter) rated the letter more highly, with an average score of 33 , compared to an average score of 31 in the control group." We have provided an additional figure showing total letter rating scores in control and case groups, for further clarification; see Figure 2.

- Tables 3, 4, and 5 depict data from survey questions 4, 5, and 6 , respectively.

- The example letter was initially written with a pseudonym and later revised to template format; the pseudonym was inadvertently left in the letter.

The online version of the original article can be found at http://dx.doi.org/ 10.1007/s10897-014-9792-6.

\section{J. Roggenbuck}

jennifer.roggenbuck@osumc.edu

1 Genetics Department, Children's Hospitals and Clinics of Minnesota, 2525 Chicago Ave. S, Minneapolis, MN 55404, USA
The authors regret the errors.

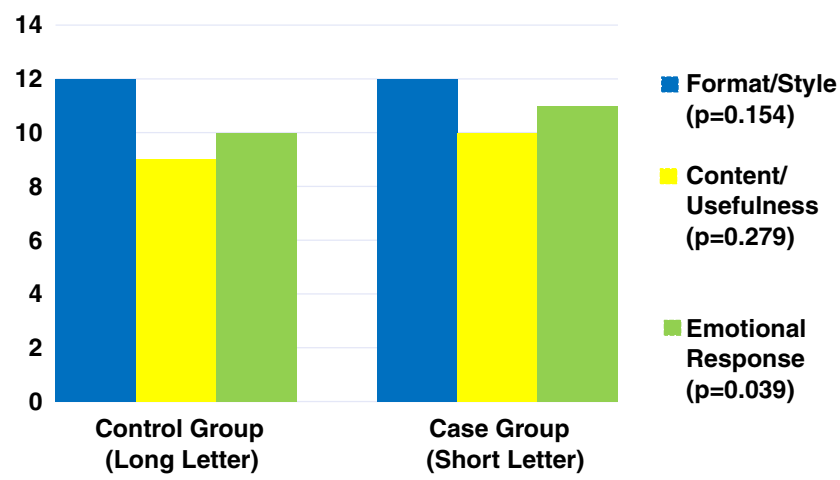

Figure 1. Comparison of control and case letter rating on dimensions of format/style, content/usefulness, and emotional response.

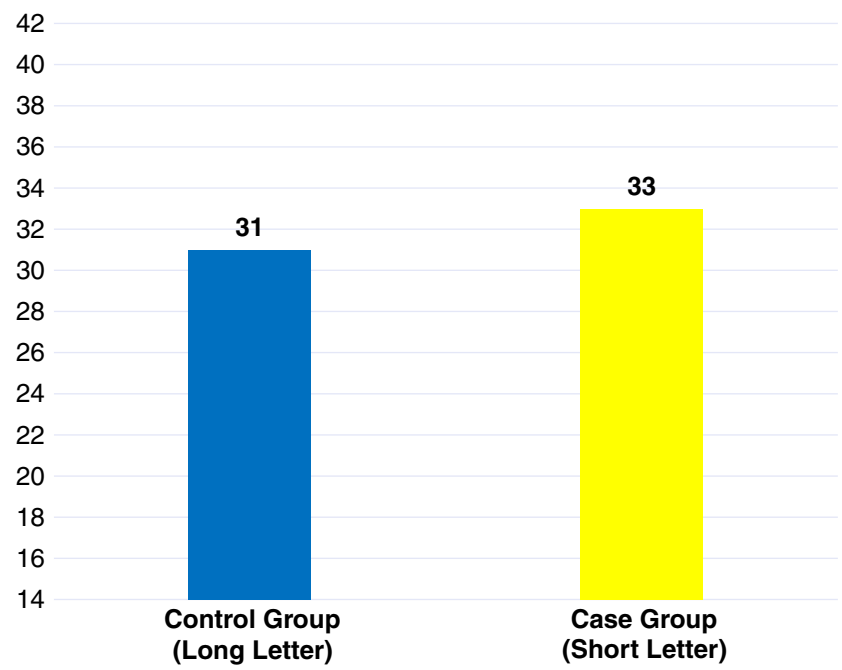

Figure 2. Total letter rating score in control and case groups $(p=0.023)$ 